\title{
Electrical energy balance contest in Solar Decathlon Europe 2012
}

\author{
Eduardo Matallanas , Jorge Solórzano , Manuel Castillo-Cagigal , Iñaki Navarro \\ Estefanía Caamaño-Martín , Miguel A. Egido , Álvaro Gutiérrez
}

\begin{abstract}
A B S T R A C T
Solar Decathlon Europe (SDE) is an international multidisciplinary competition in which 20 university teams build and operate energy-efficient solar-powered houses. The aim of SDE is not only scientific but also educational and divulgative, making visitors to understand the problems presented by real engineering applications and architecture. From a research perspective, the energy data gathered during the competition constitutes a very promising information for the analysis and understanding of the photovoltaic systems, grid structures, energy balances and energy efficiency of the set of houses. This article focuses on the electrical energy components of SDE competition, the energy performance of the houses and the strategies and behaviors followed by the teams. The rules evaluate the houses' electrical energy self-sufficiency by looking at the electricity autonomy in terms of aggregated electrical energy balance; the temporary generation-consumption profile pattern correlation; and the use of electricity per measurable area. Although the houses are evaluated under the same climatological and consumption conditions, production results are very different due to the specific engineering solutions (different electrical topologies, presence or absence of batteries, diverse photovoltaic module solutions, etc.).
\end{abstract}

\section{Introduction}

During the last decades, the availability, cost and sustainability of the energy resources have caused instabilities in the energy production and distribution chain. Moreover, environmental damages have shown the need for new energy models. The rapid increase of the electricity demand is a general constant around the world. This growth responds to various reasons, among which stand out the increasing awareness of global warming caused by greenhouse emissions, the inevitable exhaustion of traditional energy sources in the following decades (fossil fuels) and the need for countries to assure energy self-dependence [1-3].

The building sector and people activities in buildings are responsible for approximately $31 \%$ of the global final energy demand, one-third of the energy-related $\mathrm{CO}_{2}$ emissions, two-thirds of the halocarbon emissions, $25-33 \%$ of black carbon emissions and almost $60 \%$ of the worlds electricity consumption [4]. Therefore, investments in new energy infrastructures and grid improvements must be achieved $[3,5]$ and governments are increasingly interested in creating laws to improve this management [6]. Photovoltaics (PV), as well as other renewable energies, provide safe and clean electricity and, can play an important role in the solution of the aforementioned problems.

Within this scenario Solar Decathlon (SD) [7-9] was created as an international competition among universities by the U.S. Department of Energy. It promotes research and development of efficient solar houses, and tends to maximize efforts in new situations that allow university teams to implement strategies which maximize electricity autonomy and self-consumption [10,11]. The objective of the participating teams is to design and build houses that consume as few natural resources as possible and produce minimum waste products during their life cycle. Moreover, SD provides teams with the possibility of testing new technical implementations which outline scientific challenges and future research needs.

Solar Decathlon Europe (SDE) is the European version of this competition created through an agreement signed between the Spanish Ministry of Housing and the United States Government $[12,13]$ and co-organized by Universidad Politécnica de Madrid. SDE has taken place in two editions celebrated in Madrid: SDE 2010 
and SDE 2012 [14]. During the final phase of the competition, teams had to assemble their houses in Madrid, in a place open to the public ('Villa Solar') which allowed visiting all houses.

This paper focuses on the design and development of specific rules included in the SDE 2012 edition which allow the evaluation of the houses electrical self-sufficiency provided by solar active technologies and their electricity use. In order to achieve this goal, there is a specific contest on Electrical Energy Balance, which is divided into three different aspects: Electricity Autonomy, Temporary Generation-Consumption Correlation and Load Consumption per Measurable Area. A description of the contest, its implementation during the competition, an analysis of the different strategies carried out by teams and their achievements will be analyzed in the paper. The importance of electricity self-consumption and autonomy will highlight the need for specific strategies, where small changes in the daily consumption shape provide strong long term benefits.

The remainder of this article is organized as follows. In Section 2, the motivation of the competition and its different contests are explained. An exhaustive description of the Electrical Energy Balance contest is presented in Section 3. Section 4 presents the main results of the Electrical Energy Balance contest and the electricity behavior of the competition. Section 5 focuses on the most important strategies carried out by the teams during the competition. Finally, conclusions are described in Section 6.

\section{SDE 2012 contests}

The SDE competition consists of 10 separately scored contests organized around 5 main areas (i.e. architecture, energy, comfort, social-economy strategy) awarded by a total of 1000 points (see Fig. 1). Hereafter, the 10 contests are described:
- Contest 1: Architecture. An attractive design is sought, which combines comfortable and functional spaces with bioclimatic technologies and strategies for reducing the houses energy consumption. A coherent and comprehensive project is desired.

- Contest 2: Engineering and Construction. This contest evaluates the appropriateness and commissioning of the systems used for the house construction and functioning. Elements ranging from the structure of the building to its solar systems are rated.

- Contest 3: Energy Efficiency. The competition places special emphasis on teams covering house-dwellers' needs, using minimum possible resources. Concepts such as the building thermal envelope, active and passive systems (such as sunlight, ventilation, etc.) of thermal conditioning, efficiency of electrical appliances, control systems, and automation are evaluated.

- Contest 4: Electrical Energy Balance. This contest evaluates the capacity of the houses for electrical self-sufficiency. Houses should reduce consumption to a minimum and produce electricity in quantities equal or greater than their consumption.

- Contest 5: Comfort Conditions. It evaluates each house capacity to maintain environmental conditions (i.e. temperature, humidity, acoustics, air quality and illumination) suitable for the comfort of its inhabitants.

- Contest 6: Functioning of the House. Checks are made on the possibility of performing normal everyday tasks, such as using electrical appliances (e.g. washing machine, dishwasher), electronic equipment (e.g. TV, DVD) and producing hot water.

- Contest 7: Communication and Raising Social Awareness. This contest assesses teams ability to transmit to the public the basic concepts behind the SDE competition, as well as ideas contributed by their completed house along these lines, both during the period of prior design and during public visits.

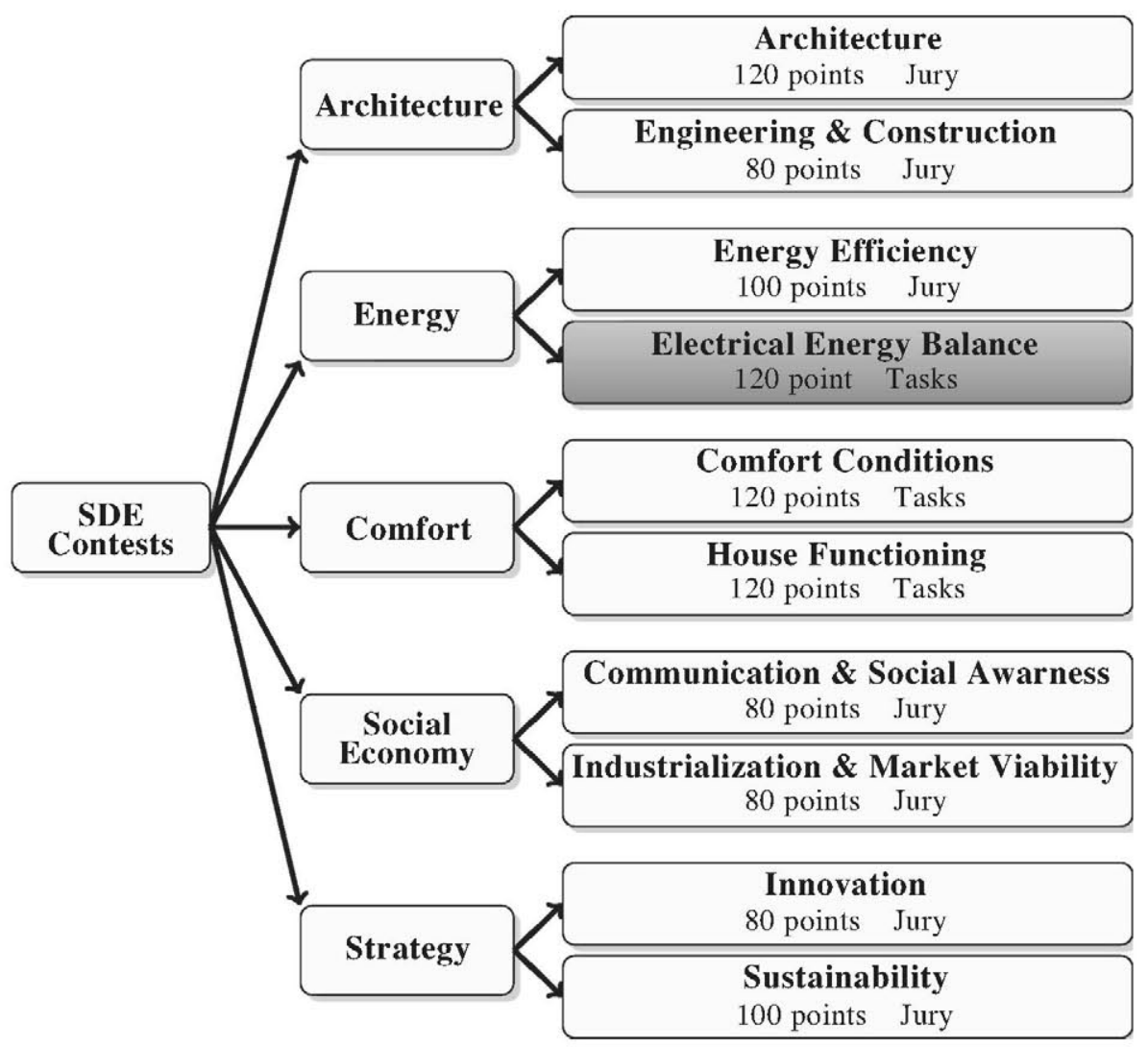

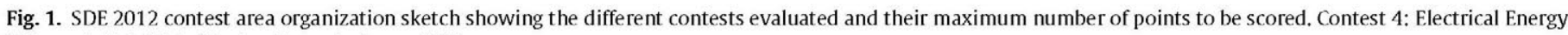
Balance is highlighted, being the main focus of this paper. 
Table 1

On-site contest calendar.

\begin{tabular}{cc|c|c|c}
\hline & \multirow{2}{*}{ Day } & $\begin{array}{c}\text { 17-20 Sep 12 } \\
\text { 24-27 Sep 12 }\end{array}$ & $\begin{array}{c}\text { 21 Sep 12 } \\
\text { 28 Sep 12 }\end{array}$ & $\begin{array}{c}\text { 22-23 Sep 12 } \\
\text { Weekend }\end{array}$ \\
\cline { 3 - 5 } & & Days 1-4 \& 8-11 & Days 5 \& 12 & Days 6 \& 7 \\
\hline $8: 00$ & $10: 00$ & & & \\
$10: 00$ & $12: 00$ & Competition & Competition & \\
$12: 00$ & $14: 00$ & Activities & Activities & Public \\
$14: 00$ & $16: 00$ & & & Visits \\
$16: 00$ & $18: 00$ & Public & Public & \\
$18: 00$ & $20: 00$ & Visits & Visits & \\
$20: 00$ & $22: 00$ & Competition & Activities & \\
$22: 00$ & $23: 00$ & \multicolumn{5}{|c}{} \\
\hline
\end{tabular}

- Contest 8: Industrialization and Market Viability. This contest assesses whether the house can be successfully transferred onto the property market. Factors such as commercial appeal of the product, price of production and possibilities for prefabricating parts of the building are evaluated.

- Contest 9: Innovation. Points are gained by teams who have made innovative solutions in various fields, ranging from architectural ideas to development of new materials and systems.

- Contest 10: Sustainability. This contest considers the environmental impact of the house in its lifetime, from extraction and transformation of its materials, building procedures and use, to its demolition and recycling.

The aforementioned contests are classified in two categories depending on how they were judged: jury contest, evaluated by a multidisciplinary jury, and measured contests, evaluated by means of measurements in real time. Measured contests were continuously monitored and supervised by observers to assure that measuring instruments were not manipulated. Measured contests include Contests 4,5 and 6. The rest of the contests belong to the jury contests category.

The on-site competition lasted 12 days, divided in three groups depending on the activities carried out (see Table 1). The first group (Mondays-Thursdays) had two competition periods in the morning and in the afternoon with a public visit period between them. The second group (Fridays) had only one period for competition activities and another one for public visits. During the the third one (weekends) only public visits were allowed and there was no competition activities. All measurements were interrupted during the public visit periods except the electrical measurements involved in Contest 4 . The reason is that comfort conditions were influenced by the public in the houses, but not the electrical measurements.

\section{Contest 4: electrical energy balance}

Electrical Energy Balance contest (see Fig. 1) evaluates the houses' electrical energy self-sufficiency provided by PV technology and their electricity use intensity. The evaluation of this contest is based on electrical energy measurements. The contest evaluates three specific features: electricity autonomy in terms of aggregated electrical energy balance; temporary generation-consumption profile patterns correlation; and use of electricity per measurable area. This contest is divided in three sub-contests, each one evaluating one of the aforementioned concepts.

The location of a house inside the 'Villa Solar' influences the PV generation because of the existence of shadows in certain periods of time. Therefore, for the seek of equanimity, a Free of Shadows (FoS) period was defined from 10:00 to 17:00, out of which PV generation was not taken into account for the competition scoring and specifically for Contest 4 . Although during the competition there was sun light from 7:30 to 21:00. The PV installation size was limited to $10 \mathrm{~kW}$ of all power conditioning equipment connected to PV generation (DC/DC and/or DC/AC), as well as the storage system maximum capacity was limited to $5 \mathrm{~kW}$. This values are reasonable to get high levels of self-consumption and limit the excessive differences between teams due to increased budget availability [14].

Hereafter, the three subcontests are detailed.

\subsection{Electricity autonomy}

It evaluates the degree of self-supply of the house and the energy excess during the competition. This sub-contest calculates the Net Balance (NB) of the competition as:

$N B=\widehat{E}_{G}-E_{L}$

where $\widehat{E}_{G}$ is the truncated energy generated by the PV system during the FoS period, and $E_{L}$ is the energy consumed by the loads during the whole competition.

Maximum points were obtained if $N B \geq 10 \mathrm{kWh}$, reduced points if $-10 \mathrm{kWh} \leq N B \leq 10 \mathrm{kWh}$ and no points if $N B<-10 \mathrm{kWh}$ (see Fig. 2a),

\subsection{Temporary generation-consumption correlation}

One of the main advantages of distributed solar generation is that electricity can be consumed at the same place where it is generated, thus minimizing the electricity transport and distribution losses. This effect is maximized if electricity is consumed at the same time as it is generated. This sub-contest evaluates self-consumption, as the temporary correlation between electricity generation and electricity demand during the contest week periods where electricity generation is computed as:

$\xi_{L}=\frac{\widehat{E}_{P V \rightarrow L}+\widehat{E}_{B \rightarrow L}}{\widehat{E}_{L}}=\frac{\widehat{E}_{G \rightarrow L}}{\widehat{E}_{L}}$

where $\widehat{E}_{P V \rightarrow L}$ is calculated as the electricity generated and simultaneously consumed by the loads within the FoS period, $\widehat{E}_{L}$ is the energy consumed by the loads truncated to the Task

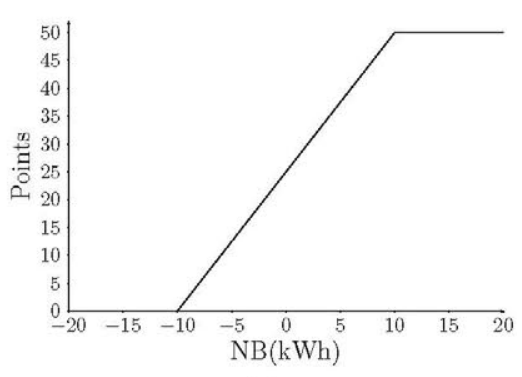

(a)

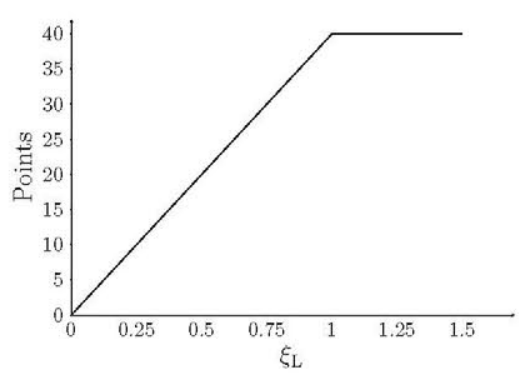

(b)

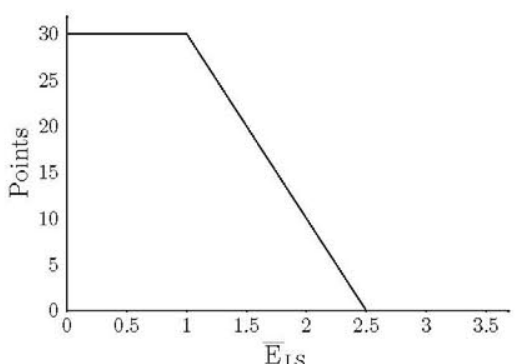

(c)

Fig. 2. Contest 4 scoring distribution: (a) electricity autonomy, (b) temporary generation-consumption correlation and (c) load consumption per measurable area. 


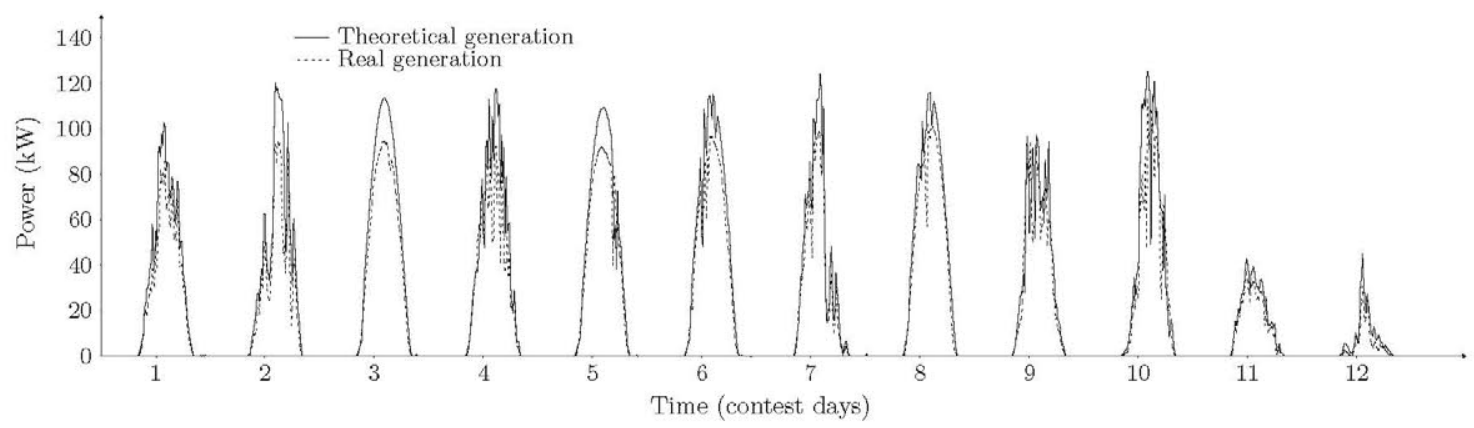

Fig. 3. Theoretical and real PV production during the competition.

Completion (TC) period (i.e. 8:00-23:00), $\widehat{E}_{B \rightarrow L}$ is calculated as the electricity exported from the batteries to the loads, whose stored energy can only come from the house PV sources during the FoS period, and $\widehat{E}_{G \rightarrow L}$ is the total locally generated electricity. Notice that $\widehat{E}_{B \rightarrow L}=0$ if the house has not a hard-wired battery bank. Points distribution is directly proportional to $\xi_{L}$ (see Fig. 2b).

\subsection{Load consumption per measurable area}

In order for countries to reduce their $\mathrm{CO}_{2}$ emissions and external energy supply dependence, having a large renewable energy production is as important as being efficient in the energy consumption. This sub-contest aimed to evaluate the electrical energy efficiency of the houses, related to their measurable area.

To accomplish the sub-contest requirements, $\widetilde{E}_{L}$ value is calculated as the daily average of the electrical loads' consumption during the competition. This average takes into account a complete day period (i.e. $24 \mathrm{~h}$ ) for every day during the contest. For each house $(i)$, the load consumption per measurable area is calculated as:

$\widetilde{E}_{L S}^{i}=\frac{\widetilde{E}_{L}^{i}}{A^{i}}$

where $A^{i}$ represents the measurable area of house $i$.

Finally, the scoring distribution is normalized to the minimum consumption performed by all Teams $\left(\widetilde{E}_{L S_{\min }}\right)$ as:

$\bar{E}_{L S}^{i}=\frac{\widetilde{E}_{L S}^{i}}{\widetilde{E}_{L S_{\min }}}$

where $\widetilde{E}_{L S_{\min }}=\min \left\{\widetilde{E}_{L S}^{i}\right\} ; \forall i$. Fig. $2 \mathrm{c}$ shows the scoring distribution related to the $\bar{E}_{L S}$ value. Notice that the house less consuming per measurable area will score 30 points, while houses consuming 2.5 times more than this one will obtain no points. ${ }^{1}$

\section{On-site competition results}

In this section, the results for the Electrical Energy Balance contest during the SDE 2012 competition are presented. The electrical data used to elaborate the results are obtained from the measures of the 18 teams participating at SDE2012. The measurements were made through an ad-hoc hardware and software platform developed specially for SDE2012 competition [15].

\subsection{Villa Solar generation}

During the week of the on-site competition (September 17th-28th) a daily average irradiance on a horizontal plane of

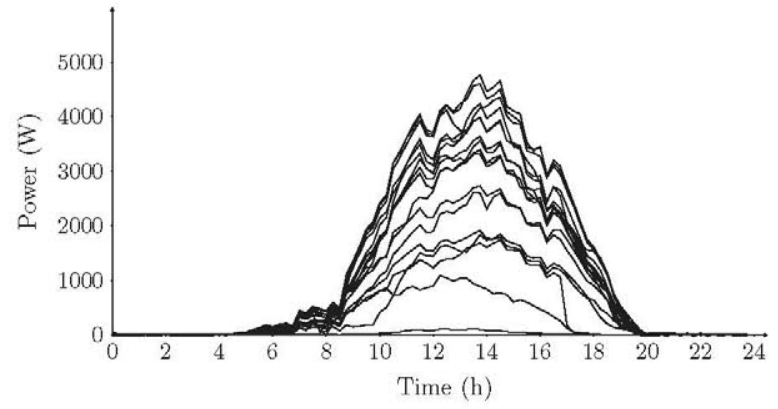

Fig. 4. Mean generated power by each team during the competition.

$4226 \mathrm{Wh} / \mathrm{m}^{2}$ was available in the competition location (Madrid, $40^{\circ} 25^{\prime} \mathrm{N}$ and $3^{\circ} 43^{\prime} 40^{\prime \prime} \mathrm{W}$ ). This value was elaborated from the measures of AEMet. ${ }^{2}$ It is an average value for this month according to [16].

Given the PV characteristics of the 18 teams shown in Table 2, the theoretical maximum generation is shown in Fig. 3. The theoretical curve has been elaborated using the irradiance and the characteristics of the systems. It was calculated as the irradiance at the PV system plane for each generator of the houses (considering a Productivity Reference $P R=1$, see Section 4.2), not taking into account the losses (inverters, cables, connections, etc.). Moreover, the real generation of the 'Villa Solar' for the week of the on-site competition is also shown in Fig. 3 superposed to the theoretical one. We observe a maximum difference of less than $20 \mathrm{~kW}$ superposed to the theoretical maximum power $(P R=1)$ for the whole contest week.

However, given the teams characteristics we observe high differences in the daily generated power average between them. This difference is not only related to the installed power, but the system configuration or the losses inside the PV system, among others. Fig. 4 shows the daily generated power average by each team. It is observed that the house with the highest generation produces in its maximum value more than 5 times the house with the lowest generation.

Fig. 5 presents the final energy results of the on-site competition. It is shown how a theoretical $7 \mathrm{MWh}$ generation energy gets reduced up to $5.84 \mathrm{MWh}$ of real generation. Moreover, if measurements are restricted to the FoS period, only a $4.93 \mathrm{MWh}$ generation is achieved. Remember that the FoS period aims to evaluate equally the PV production independently of the location within the "Villa Solar'. On the other hand, real consumption is nearly half of the generation ( $3.23 \mathrm{MWh}$ ) while consumption restricted to the TC period is less than half of the generation (2.43 MWh).

\footnotetext{
1 The value 2.5 was obtained from the experience of the previous edition of SDE.
}

\footnotetext{
${ }^{2}$ Spanish Meteorological Agency: http://www.aemet.es
} 
Table 2

PV parameters of the 18 teams. $m$-Si refers to monocrystalline, $p$-Si to polycrystalline, $\mu$-Si to micro and $a$-Si amorphous silicon,

\begin{tabular}{|c|c|c|c|c|c|c|c|c|}
\hline & Orientation & Inclination & Module power $\left(W_{p}\right)$ & PV cell type & No. PV modules & Array area $\left(\mathrm{m}^{2}\right)$ & Total PV area $\left(\mathrm{m}^{2}\right)$ & Total PV power $\left(\mathrm{kW}_{p}\right)$ \\
\hline H01 & - & - & - & $\mathrm{m}-\mathrm{Si}$ & - & - & - & 5.80 \\
\hline $\mathrm{HO} 2$ & 0 & 8 & 333 & $\mathrm{~m}-\mathrm{Si}$ & 34 & 55.46 & 55.46 & 11.32 \\
\hline \multirow{2}{*}{$\mathrm{HO} 3$} & 0 & 90 & 135 & $\mathrm{a}-\mathrm{Si}$ & 14 & 20.20 & \multirow{2}{*}{67.70} & \multirow{2}{*}{9.03} \\
\hline & 0 & 6 & 255 & $\mathrm{~m}-\mathrm{Si}$ & 28 & 47.50 & & \\
\hline HO4 & 180 & 15 & 230 & $\mathrm{~m}-\mathrm{Si}$ & 48 & 131.80 & 131.80 & 11.04 \\
\hline H05 & 0 & 20 & 250 & $\mathrm{~m}-\mathrm{Si}$ & 32 & 55.00 & 55.00 & 8.00 \\
\hline \multirow{2}{*}{ H06 } & - & 90 & - & - & - & - & \multirow{2}{*}{ - } & \multirow{2}{*}{9.50} \\
\hline & 0 & - & 225 & $\mathrm{~m}-\mathrm{Si}$ & 21 & 26.12 & & \\
\hline $\mathrm{H} 07$ & - & - & - & - & - & - & - & 10.00 \\
\hline $\mathrm{H} 08$ & 41 & 18 & 300 & $\mathrm{~m}-\mathrm{Si}$ & 14 & 70.00 & 70.00 & 9.20 \\
\hline H09 & 90 & 0 & 214 & p-Si & 56 & 91.28 & 91.28 & 11.98 \\
\hline $\mathrm{H} 10$ & 0 & 0 & 220 & $\mathrm{p}-\mathrm{Si}$ & 42 & 67.59 & 67.59 & 9.24 \\
\hline \multirow{2}{*}{ H11 } & 0 & 1 & 505 & $\mathrm{p}-\mathrm{Si}$ & 8 & 34.50 & \multirow{2}{*}{103.50} & \multirow{2}{*}{13.29} \\
\hline & 0 & 1 & 578 & p-Si & 16 & 69.00 & & \\
\hline \multirow{2}{*}{ H12 } & \pm 90 & 90 & 185 & $\mathrm{p}-\mathrm{Si}$ & 12 & 16.15 & \multirow[b]{2}{*}{86.14} & \multirow{2}{*}{11.84} \\
\hline & 0 & 0 & 185 & $\mathrm{p}-\mathrm{Si}$ & 40 & 53.84 & & \\
\hline $\mathrm{H} 13$ & \pm 90 & 10 & 125 & $\mu-S i$ & 9 & 38.61 & 77.22 & 6.75 \\
\hline H14 & - & - & - & - & - & - & - & 3.50 \\
\hline \multirow{3}{*}{ H15 } & 0 & 20 & 220 & $\mathrm{~m}-\mathrm{Si}$ & 22 & 31.12 & \multirow{3}{*}{56.65} & \multirow{3}{*}{8.76} \\
\hline & 0 & 30 & 205 & $\mathrm{p}-\mathrm{Si}$ & 20 & 25.53 & & \\
\hline & 0 & 5 & 264 & $\mathrm{~m}-\mathrm{Si}$ & 21 & 44.00 & & \\
\hline \multirow[t]{3}{*}{ H16 } & 0 & 5 & 176 & $\mathrm{~m}-\mathrm{Si}$ & 18 & 25.00 & \multirow[t]{3}{*}{84.26} & \multirow[t]{3}{*}{10.70} \\
\hline & 0 & 5 & 250 & $\mathrm{~m}-\mathrm{Si}$ & 8 & 15.26 & & \\
\hline & 0 & 10 & 230 & $\mathrm{~m}-\mathrm{Si}$ & 18 & 28.80 & & \\
\hline \multirow[t]{2}{*}{ H17 } & 0 & 90 & 24 & $\mathrm{a}-\mathrm{Si}$ & 19 & 9.50 & \multirow[t]{2}{*}{77.90} & \multirow[t]{2}{*}{5.30} \\
\hline & $0 ; \pm 90$ & 90 & 30 & $\mathrm{a}-\mathrm{Si}$ & 33 & 39.60 & & \\
\hline \multirow{2}{*}{ H18 } & 0 & 30 & 255 & $\mathrm{~m}-\mathrm{Si}$ & 9 & 14.62 & \multirow{2}{*}{29.24} & \multirow{2}{*}{4.60} \\
\hline & 180 & 30 & 255 & $\mathrm{~m}-\mathrm{Si}$ & 9 & 14.62 & & \\
\hline
\end{tabular}

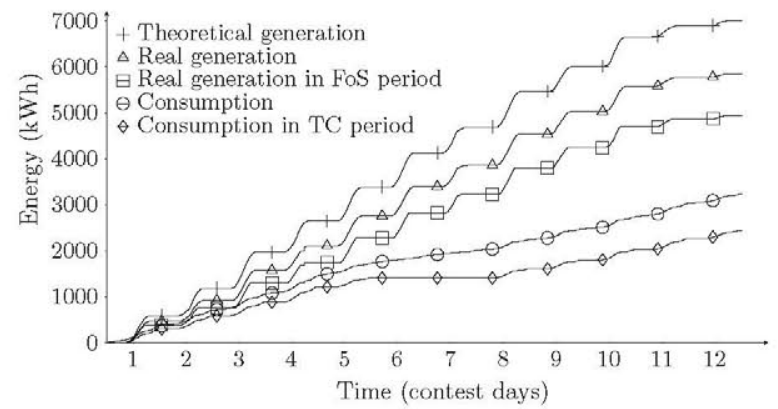

Fig. 5. Energy produced and consumed during the competition.

The electricity generated is nearly double than the electricity consumed in both cases (with and without restricted periods), making the 'Villa Solar' Net Balance greater than zero. Furthermore, approximately $50 \%$ of the energy was consumed at the very same time it was produced, providing a self-consumption factor of $\xi_{L}=0.51$ for the whole 'Villa Solar' without considering the FoS period and a $\xi_{L}=0.54$ with the time constraints for both generated and consumed electricity. Fig. 6 shows the generated energy, the consumed energy, the self-consumed energy and Net Balance of the 'Villa Solar'.

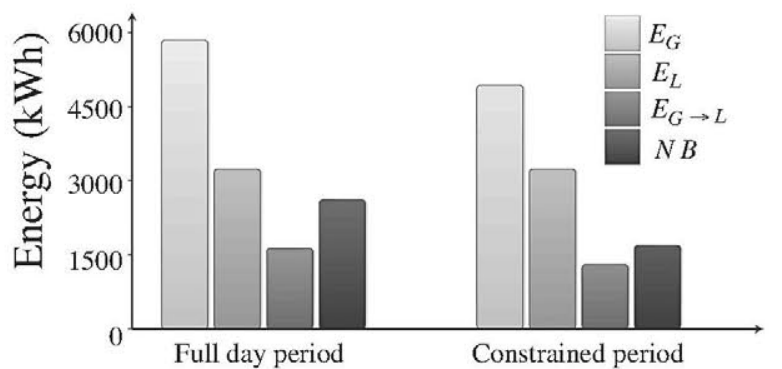

Fig. 6. Total generated, consumed, self-consumed energy and Net Balance of the 'Villa Solar' without and with constraint periods.

\subsection{Teams behavior}

Given the results of Section 4.1, the electrical behavior of the 'Villa Solar' was very satisfactory. However, as aforementioned, the behavior of teams was very different among them. The difference was not only due to the heterogeneity of the systems (see Table 2), but also to the strategies carried out during competition. 16 teams provided a positive Net Balance and 5 of them generated at least twice the energy consumed. Moreover 12 teams consumed at least half of the energy at the same time it was generated $\left(\xi_{L}>0.5\right)$. Fig. 7 shows information about energy generated, consumed, selfconsumed and Net Balance for every team for the FoS period.

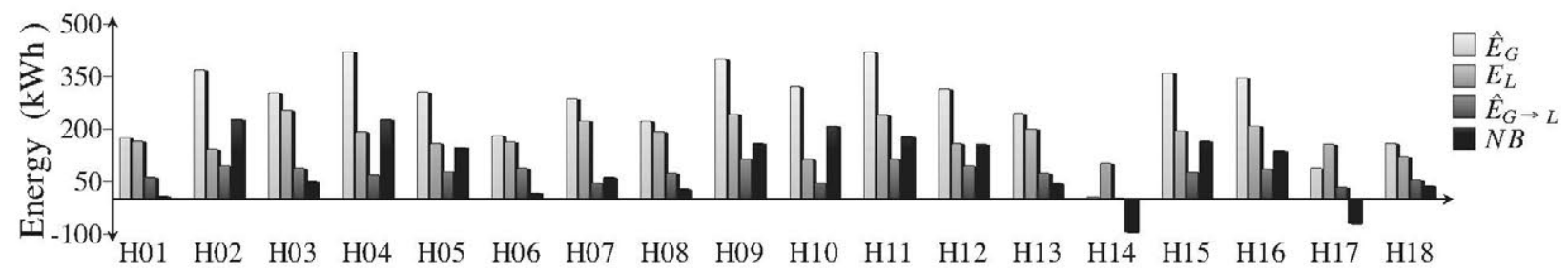

Fig. 7. Total energy generated, consumed, self-consumed and Net Balance with time constrains (FoS and TC periods) per team. 
The Performance Ratio (PR) describes the relationship between the useful energy and the theoretical energy that could be generated [17]. PR is calculated as shown in Eq. 5.

$P R=\frac{E_{P V} \cdot I_{S T C}}{P_{\text {nomG }} \cdot G_{X}}$

where, $E_{P V}$ is the PV electricity generated, $P_{\text {nomG }}$ is the nominal power of the PV generator, $G_{X}$ is the total incident irradiation upon the $\mathrm{PV}$ generator in $\mathrm{kWh} / \mathrm{m}^{2}$ and $I_{S T C}$ is the irradiance in standard test conditions whose value is $1000 \mathrm{~W} / \mathrm{m}^{2}$. However, this definition of $P R$ must be corrected in temperature, otherwise the PV system is supposed to be operating at the standard temperature of $25^{\circ} \mathrm{C}$. The performance ratio corrected in temperature $\left(P R_{T}\right)$ is define as follows.

$P R_{T}=\frac{P R}{1-\gamma \cdot\left(T_{a m b}-T_{S T C}\right)}$

where, $\gamma$ is the thermal coefficient of PV modules, $T_{a m b}$ is the ambient temperature and $T_{S T C}$ is the temperature in standard test conditions $\left(25^{\circ} \mathrm{C}\right)$.

$P R_{T}$ is a parameter which measures the PV system quality which allows to compare different PV systems independently of their location and size. For a specific PV system, the closer the $P R_{T}$ to $100 \%$ is, the more efficiently the PV system operates. However, a value of $100 \%$ cannot be achieved, as unavoidable losses always arise with the operation of the PV system (e.g. thermal loss due to heating of the PV modules, DC/AC conversion losses, etc.). High-performance PV systems can however reach a performance ratio between 70 and $80 \%$.

To calculate the $P R_{T}$ of the 18 teams, the information in Table 2 and the irradiance and the ambient temperature measured by the AEMet for the date and place of the on-site competition were used. Fig. 8 shows the $P R_{T}$ for every team, showing that 12 teams had $P R_{T} \geq 0.7$ and only 3 teams had a $P R_{T} \leq 0.5$. These results indicate the high-performance of the PV systems from the houses participating in SDE2012 and how efficient the installed systems were. $P R_{T}=0.73$ was achieved for the whole 'Villa Solar' during the on-site competition period, calculated as the sum of PV systems of all the houses.

\subsection{Electrical energy balance contest}

In this section, scoring results of the on-site contests for Contest 4 are presented. As a summary, the majority of teams got more than half the points of the 120 assigned to the contests. Only two teams did not reach this scoring, because of problems within the PV systems. Nonetheless, it is important to state that these two teams were both coming from an exhibition list, and they were offered to participate in the competition 6 months prior to the on-site contest, resulting in a very difficult situation for sponsorship and technical development.

Subcontest 4.1 evaluates self-supply of the house, the maximum points were given when the $N B \geq 10 \mathrm{kWh}$. Only the aforementioned two teams did not get any point in this subcontest. In most of the cases the teams far exceeded the condition to get maximum points. Only one team that managed to score did not achieve the maximum score. So that, in terms of exported electricity to the grid most of the teams surpassed the maximum limit imposed for this subcontest. See Table 3 for a detailed list of the results.

Subcontest 4.2 evaluates the amount of consumed electricity that is supplied by the generated PV electricity. To get the maximum points, the entire demanded electricity had to be supplied with the local generation in the evaluation periods. However, all points are not possible to be gained with only a PV system because the TC period is greater than the FoS period. Thus, the demanded electricity is greater than the generated electricity and $\xi_{L}<1$ (see Eq. 2), so that this contest penalizes the consumption out of the FoS.

Teams came up with different strategies to match the consumption and the generation (see Section 5 for a further analysis). Three teams included in their design a hard-wired battery bank to storage the excess of PV electricity and use it when the demanded electricity was greater than the generated one. These teams had a slight advantage because the stored PV electricity could be used in any time inside the TC period. However, batteries need to be charged, so these teams had an extra consumption that had to be supplied with PV electricity. Moreover, notice the hard-wired battery bank could only be charged from the PV energy produced during the FoS periods. The rest of the teams tried to adjust their consumption to the FoS period and to match the consumption with the PV generation.

As a result, 12 teams obtained a $\xi_{L} \geq 0.5$. A maximum of $\xi_{L}=0.79$ was reached and only 3 teams had a $\xi_{L}<0.35$. For the majority of the teams, more than half of the demanded electricity was supplied by the generated electricity, by matching the PV generation with great amount of consumption inside of the FoS period and reducing it as close as possible to zero out of this period.

In Subcontest 4.3, the consumption per measurable area of each house with respect the minimum consumption performed by all teams is evaluated. For this subcontest the lower the consumption was, the greater the amount of points was earned. The team which won this subcontest performed bad in the other two subcontests, but its consumption during the on-site competition was really low. 10 teams had a $\widetilde{E}_{L S}$ less than 2 times the $\widetilde{E}_{L S_{\min }}$, whereas 6 teams had a $\widetilde{E}_{L S}$ greater than 2.5 times the $\widetilde{E}_{L S_{\min }}$. A third of the teams failed to score in this subcontest, which are too many points lost because they sacrificed a quarter of the total points of Contest 4. However, some teams preferred to lose some points in this subcontest in favor of winning more points on other Contests.

Finally, the total points gained in this contest by the teams are shown in Table 3. By analyzing the teams' results, the contest was a complete success for a competition of solar houses. No team got the maximum 120 available points of this contest. However, there was a team which surpasses the barrier of 100 points and only 3 teams did not get half of the total points. The rest of the teams got a score between 60 and 100 points.

\section{Strategies}

After analyzing the teams' results, big differences in their behaviors have been observed. This section provides information about the identified team strategies. Notice that strategies are analyzed

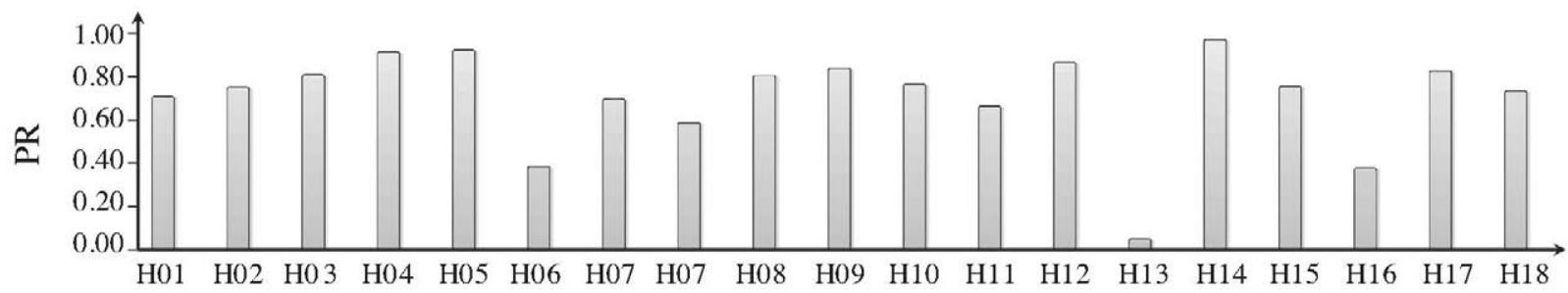

Fig. 8. Productivity reference. 
Table 3

Results for the Electrical Energy Balance contest.

\begin{tabular}{|c|c|c|c|c|c|c|c|}
\hline & \multicolumn{2}{|l|}{ S4.1 } & \multicolumn{2}{|l|}{ S4.2 } & \multicolumn{2}{|l|}{ S4.3 } & \multirow[t]{2}{*}{ Total points } \\
\hline & $\mathrm{NB}(k W h)$ & Points & $\xi_{L}$ & Points & $\widetilde{E}_{L S}$ & Points & \\
\hline H01 & 8.74 & 46.85 & 0.48 & 19.10 & 1.92 & 20.85 & 86.80 \\
\hline $\mathrm{HO} 2$ & 228.22 & 50.00 & 0.79 & 31.57 & 1.74 & 24.94 & 106.51 \\
\hline $\mathrm{H} 03$ & 50.57 & 50.00 & 0.52 & 20.96 & 3.75 & 0.00 & 70.96 \\
\hline $\mathrm{HO} 4$ & 227.36 & 50.00 & 0.52 & 20.91 & 2.89 & 0.00 & 70.91 \\
\hline H05 & 148.52 & 50.00 & 0.58 & 23.19 & 2.29 & 17.41 & 90.61 \\
\hline H06 & 18.26 & 50.00 & 0.76 & 30.49 & 2.03 & 14.94 & 95.44 \\
\hline $\mathrm{H} 07$ & 63.20 & 50.00 & 0.34 & 13.77 & 2.73 & 0.00 & 63.77 \\
\hline $\mathrm{H} 08$ & 28.37 & 50.00 & 0.54 & 21.77 & 2.22 & 12.15 & 83.93 \\
\hline Ho9 & 158.24 & 50.00 & 0.59 & 23.50 & 3.57 & 0.00 & 73.50 \\
\hline H10 & 208.70 & 50.00 & 0.47 & 18.83 & 2.41 & 15.51 & 84.33 \\
\hline H11 & 179.30 & 50.00 & 0.57 & 22.79 & 3.48 & 0.00 & 72.79 \\
\hline $\mathrm{H} 12$ & 157.52 & 50.00 & 0.70 & 28.69 & 2.44 & 15.18 & 93.87 \\
\hline $\mathrm{H} 13$ & 44.12 & 50.00 & 0.57 & 22.63 & 2.82 & 0.00 & 72.63 \\
\hline H14 & -94.39 & 0.00 & 0.05 & 1.78 & 1.32 & 30.00 & 31.78 \\
\hline $\mathrm{H} 15$ & 164.99 & 50.00 & 0.57 & 22.62 & 2.47 & 7.11 & 79.73 \\
\hline $\mathrm{H} 16$ & 138.76 & 50.00 & 0.60 & 24.01 & 2.08 & 13.10 & 87.11 \\
\hline $\mathrm{H} 17$ & -70.01 & 0.00 & 0.29 & 10.56 & 2.70 & 2.26 & 12.82 \\
\hline $\mathrm{H} 18$ & 37.24 & 50.00 & 0.50 & 19.95 & 2.36 & 17.20 & 87.15 \\
\hline
\end{tabular}

from the measurements obtained from the houses. ${ }^{3}$ Thus, they are probably not the intended strategies carried out by teams, but the ones observed from the Electrical Energy Balance contest point of view.

By analyzing the measurements, it is observed that some of the houses are giving priority to the Electricity Autonomy contest, others prioritize the Self-Consumption one, while some pursuit a compromise between them.

The first strategy carried out by teams is in the design of the electricity energy system. It is the decision of including or not a hard-wired battery bank. Having a hard-wired battery bank allows to soften the mismatch between generation and consumption; hence to increase self-consumption [11]. Therefore, it is not strange to find that the three teams with a hard wired battery bank (H02, H06 and H16) are within the first ranking position in the Electrical Energy Balance contest (1st, 2nd and 6th, respectively).

As shown in Section 4, it is clear that most teams got a high score in the contest. However, those results provide absolute measurements but not relative ones to the PV system and strategies of teams. Therefore, by analyzing the measurements we observe how two teams were able to have an excess of more than $10 \mathrm{kWh}$ in the first day, two others were able to do it in the second day, four in the third day, while the rest were able to do it after the fifth day. The reason is that teams having a big PV generator were able to easily accomplish the Electricity Autonomy subcontest. On the other hand, teams with a more modest PV generator focused on reducing the consumption in order to obtain as soon as possible the 50 points of this subcontest.

Moreover, nine teams reached a self-consumption factor in the first day of the competition that was maintained during the rest of it. By analyzing Eq. 2, this constant plateau over time means that the self-consumption strategy was not prioritized and it was obtained thanks to natural self-consumption.The natural self-consumption in any electrical system with local generation represents the part of the consumption that always matches the generation regardless of any specific action on the demand. On the other hand, three teams reduced the self-consumption value achieved the first day during the competition, because these teams did not focus at all on selfconsumption, and consumption and generation were mismatched over time. Finally, only six teams increased their self-consumption

\footnotetext{
${ }^{3}$ All measurements are public at http://monitoring.sdeurope.org.
}

factor during the competition, by adjusting consumption to generation during all days.

After the on-site competition, an interesting analysis has been done related to the dimensioned PV systems, comparing the generated electricity that supplied the loads to the total generated electricity ( $\xi_{G}$, see Eq. 7$)$ and to the total consumed energy $\left(\xi_{L}\right.$, see Eq. 2). The first factor, $\xi_{G}$, represents the efficiency of the local generated electricity to meet the demand of a user [18]. It is defined as:

$\xi_{G}=\frac{\widehat{E}_{P V \rightarrow L}+\widehat{E}_{B \rightarrow L}}{\widehat{E}_{G}}=\frac{\widehat{E}_{G \rightarrow L}}{\widehat{E}_{G}}$

where $\widehat{E}_{G}$ is the local generated electricity within the FoS period. The objective of this analysis is to identify which teams have achieved a high value of self-consumption relative to the efficiency of the local PV system to meet the demand. This fact is calculated by means of the Behavior Ratio (BR) factor:

$B R_{i}=\xi_{G, i} \cdot \xi_{L, i}$

where $\xi_{G, i}$ is the PV local consumption factor of house $i$ and $\xi_{L, i}$ is the self-consumption factor of house $i$. Both factors belongs to [0, 1] interval because they are normalized by the total amount of generated energy $\left(\xi_{G}\right)$ or the total demanded energy $\left(\xi_{L}\right)$. Notice that from a behavioral perspective, the closer the value of $B R$ is to 1 , the better dimensioned the system is. This is because a system with a $\xi_{G} \simeq 1$ and $\xi_{L} \simeq 1$ represents that the generation matched exactly the consumption, and that all energy consumed was produced by the PV system. It is important to notice that low values of $B R$ could mean that there is a great excess of PV electricity, that the consumption is too high for the system installed or the consumption does not match the generated electricity. Table 4 shows information of $B R$ s for all teams.

H06 is the team which obtained the best BR value, far from the value of the rest of the teams. This team gets its system fitted for the consumption during the on-site competition week. Nearly half of the total PV generation was intended for the load consumption $\left(\xi_{G}=0.49\right)$. This amount of generated electricity represents $3 / 4$ of the demand $\left(\xi_{L}=0.76\right)$. In spite of doing a great work in this contest, they get the 2 nd place (see Table 3 ). The first on the Contest 4 ranking (H02) only gets the third best BR because the surplus of generated electricity was too high; its system was oversized. However, the second high $B R$ value was for a team (H12) without a storage system. Most of its consumption is within the FoS period, while for 
Table 4

Dimensioned behavior ratio for all teams.

\begin{tabular}{|c|c|c|c|c|c|c|c|c|c|c|c|c|c|c|c|c|c|c|}
\hline Factor & H01 & $\mathrm{HO} 2$ & $\mathrm{HO}_{3}$ & HO4 & H05 & H06 & $\mathrm{HO}$ & H08 & H09 & $\mathrm{H} 10$ & H11 & $\mathrm{H} 12$ & H13 & H14 & H15 & H16 & H17 & H18 \\
\hline$\xi_{G}$ & 0.365 & 0.258 & 0.290 & 0.168 & 0.258 & 0.485 & 0.161 & 0.342 & 0.285 & 0.142 & 0.268 & 0.302 & 0.308 & 0.597 & 0.217 & 0.248 & 0.399 & 0.336 \\
\hline$\xi_{L}$ & 0.477 & 0.789 & 0.524 & 0.523 & 0.580 & 0.762 & 0.344 & 0.544 & 0.587 & 0.471 & 0.570 & 0.703 & 0.566 & 0.050 & 0.566 & 0.600 & 0.293 & 0.499 \\
\hline$B R$ & 0.174 & 0.204 & 0.152 & 0.088 & 0.150 & 0.370 & 0.055 & 0.186 & 0.168 & 0.067 & 0.153 & 0.212 & 0.174 & 0.030 & 0.122 & 0.149 & 0.117 & 0.168 \\
\hline
\end{tabular}

the rest of the time the consumption was much lower. Thus, there is no great changes at the top of the classification, but from the third to the end there are many changes with respect to the contest classification. This fact shows that some teams that have great values of $\xi_{L}$ was because the over-sizing of their PV system. The oversized PV system allows the teams to do all the tasks inside the FoS without managing it. For this reason is necessary to introduce a parameter to evaluated how well the designed PV installation with the consumption is fitted.

\section{Conclusions}

This paper has analyzed the results of the Electrical Energy Balance contest of the Solar Decathlon Europe 2012. The set of houses participating in the contest compose a local grid with a very high proportion of solar energy. The high exploitation of the solar resource by the PV generators can be observed, where the real generation is very close to the theoretical one.

The objective of the energy balance contest is to evaluate the houses electrical self-sufficiency provided by PV generation and their consumption. High differences were observed in the daily generated and consumed power between the teams. Despite this fact, most teams achieved high levels of Net Balance, concluding that the teams have designed PV systems which are large enough to supply all their electrical needs. From the point of view of generation-consumption correlation, most teams maintained the same level throughout the contest. This means that they did not performed a specific strategy to increase this correlation.

In conclusion, the Solar Decathlon Europe 2012 is a prime example of the use of PV generation in the residential sector. The proper electrical facility design and architectural integration have been present in all the facets of the contest. However, there are still some challenges in optimizing the use of PV systems which will be tackled in future editions of Solar Decathlon Europe by the introduction of new rules. These challenges should be focused on Demand-Side Management implementations, where the reduction of the energy cost function or the increase of the global (inside the 'Villa Solar') self-consumption should be addressed.

\section{Acknowledgments}

E. Matallanas is sponsored by the Spanish Ministry of Education with a Ph.D. grant (FPU-2011). M. Castillo-Cagigal is sponsored by the Spanish Ministry of Education with a Ph.D. grant (FPU-2010). J. Solórzano thanks the Fundación Iberdrola (F. Iber 2013) for the awarded grant for his Ph.D. studies during the 2012-2013 academic year. This work has been partly funded by the Spanish Science and Innovation Ministry under the IPT-2011-1468-920000 grant and the Economy and Competitiveness Ministry under the IPT-20121072-120000 grant.

\section{References}

[1] IPCC, Special report on renewable energy sources and climate change mitigation, Tech, rep., Cambridge University Press, Cambridge, UK/New York, 2011.

[2] J. Kjärstad, F. Johnsson, Resources and future supply of oil, Energy Policy 37 (2) (2009) 441-464

[3] W. Kamal, Improving energy efficiency - the cost-effective way to mitigate global warming, Energy Conversion \& Management 38 (1) (1997) 39-59.

[4] D. Ürge-Vorsatz, N. Eyre, P. Graham, D. Harvey, E. Hertwich, Y. Jiang, C. Kornevall, M. Majumdar, J.E. McMahon, S. Mirasgedis, S. Murakami, A Novikova, Global Energy Assessment - Toward a Sustainable Future, Cambridge University Press, Cambridge, MA, 2012, pp. 649-760, Chapter 10-Energy EndUse: Building.

[5] N. Lior, Energy resources and use: the present situation and possible paths to the future, Energy 33 (9) (1997) 842-857.

[6] European Commission, Towards a EUstrategy for the security of energy supply, Tech. rep. COM (2002) 321, E.U., 2002.

[7] R.J. King, C. Warner, Solar decathlon: energy we can live with, in: Proceedings of the 3rd World Conference on Photovoltaic Energy Conversion, IEEE Press, Piscataway, NJ, 2003, pp. 2139-2142.

[8] M.R. Wassmer, M.J. Brandemuehl, A. Jackaway, The simulation of a zero-energy residential building for the solar decathlon competition, in: Proceedings of the International Solar Energy Conference, American Society of Mechanical Engineers, New York, NY, 2003, pp. 45-53.

[9] C.L. Warner, M.R. Wassmer, Solar decathlon 2005-PV system strategies and results, in: Proceedings of the 4th World Conference on Photovoltaic Energy Conversion, IEEE Press, Piscataway, NJ, 2006, pp. 2272-2276.

[10] M. Castillo-Cagigal, A. Gutiérrez, F. Monasterio-Huelin, E. Caamaño-Martín, D. Masa-Bote, J.Jiménez-Leube, A semi-distributed electric demand-side management system with PV generation for self-consumption enhancement, Energy Convers. Manage. 52 (7) (2011) 2659-2666.

[11] M. Castillo-Cagigal, E. Caamaño-Martín, E. Matallanas, D. Masa-Bote, A. Gutiérrez, F. Monasterio-Huelin, J. Jiménez-Leube, PV self-consumption optimization with storage and active DSM for the residential sector, Sol. Energy 85 (9) (2011) 2338-2348.

[12] C.L. Warner, S. Farrar-Nagy, M. Wassmer, B. Stafford, R. King, S. Vega-Sanchez, E. Rodriguez-Ubiñas, J. Cronemberger, J.S. María-Tomé, The 2009 department of energy solar decathlon and the 2010 European solar decathlon - expanding the global reach of zero energy homes through collegiate competitions, in: Proceeding of the 34th Photovoltaic Specialists Conference, IEEE Press, Piscataway, NJ, 2009, pp. 002121-002125.

[13] Y. Xiangqun, G. Hui, Energy and environment strategies of a Chinese proto type of solar house: introduction of an entry of the SDE 2010 competition, in: Proceedings of the International Conference on Computer Distributed Control and Intelligent Environmental Monitoring, IEEE Press, Piscataway, NJ, 2011, pp. 1482-1486.

[14] I. Navarro, A. Gutiérrez, C. Montero, E. Rodríguez-Ubiñas, E. Matallanas, M. Castillo-Cagigal, M. Porteros, J. Solórzano, E. Caamaño-Martín, M.A. Egido, J.M. Páez, S. Vega, Solar Decathlon Europe 2012: a multidisciplinary educational competition, Tech. rep., Robolabo, ETSI Telecomunicación, Universidad Politécnica de Madrid, Madrid, Spain, 2013.

[15] A. Gutierrez, M. Castillo-Cagigal, E. Matallanas, I. Navarro, Monitoring of a solar smart house village, Tech. Rep. TR/ROBOLABO/2013-003, Robolabo, ETSI Telecomunicación, Universidad Politécnica de Madrid, Madrid, Spain, 2013.

[16] J.M. Sancho, J. Riesco, C. Jiménez, M.C. Sánchez, J. Montero, M. López, Solar radiation atlas in Spain using data from the climate SAF EUMETSAT, Tech. rep., AEMet, Madrid, Spain, 2012.

[17] IEC, IEC 61724: Photovoltaic System Performance Monitoring - Guidelines for Measurement, Data Exchange and Analysis, International Electrotechnical Commission, Geneva, Switzerland, 1998.

[18] E. Matallanas, M. Castillo-Cagigal, E.C. no Martín, D. Masa-Bote, A. Gutiérrez, F. Monasterio, Analysis of the self-consumption possibilities in small grid-connected photovoltaic systems in Spain, in: Proceedings of the 26th European Photovoltaic Solar Energy Conference, WIP-Renewable Energies, Munich, Germany, 2011, pp. 4619-4624. 